\title{
Lightning stroke and neuropsychological impairment: cases and questions
}

\author{
Adriaan $\mathrm{H}$ van Zomeren, Henk-Jan ten Duis, Jan M Minderhoud, Mirjam Sipma
}

\begin{abstract}
Objective-To objectify neuropsychological impairments in survivors of lightning stroke with lasting complaints about poor concentration and inability to divide their attention.

Design-A series of six cases of lightning stroke were studied. All patients had lost consciousness and reported amnesia of varying length. Assessment took place between one and four years after injury, ensuring that their neurological state had stabilised. They were tested with a neuropsychological battery with an emphasis on attention and memory. Personality and emotional reaction to the accident were assessed with questionnaires and a lightning fear scale. Complaints were recorded by means of a trauma complaints list including 10 questions on symptoms of the post-traumatic stress disorder.
\end{abstract}

Results-Patients reported fatigue and lack of energy as their main complaints. In addition, poor concentration, irritability, and emotional lability were mentioned often. Neuropsychological tests disclosed mild impairments in memory, attention, and visual reaction times. Two patients could be classified as depressed, and one of these also showed convincing signs of the post-traumatic stress disorder.

Conclusion-As the lasting complaints and impairments could not be explained, for all six cases, as resulting from head injury concomitant with lightning stroke, cerebral hypoxia or a post-traumatic stress syndrome, it is concluded that lightning stroke can result in subtle cognitive impairments. It is speculated that most complaints of these survivors are caused by a vegetative dysregulation, a disorder that has often been noted in the literature on the effects of electrical injury to the nervous system. Such a dysregulation might cause both the main complaint of fatigue and the mild cognitive impairments identified with the present test battery.

(F Neurol Neurosurg Psychiatry 1998;64:763-769)

Keywords: lightning stroke; neuropsychology; posttraumatic stress disorder

rrespondence to: Dr A H van Zomeren, Academisch Ziekenhuis Groningen, Hanzeplein 1, Postbus 30 001, $9700 \mathrm{RB}$ Groningen, The

Netherlands.

Received 26 February 1997 and in final revised form 7 October 1997

Accepted 16 October 1997
Lightning consists of direct current, as opposed to the alternating current in other electrical accidents. As alternating current often causes tetany in the victim, exposure time in industrial and domestic accidents may be prolonged to many seconds. Secondly, the energy level is far higher in lightning stroke than in other electrical accidents with voltages ranging up to 100 $000000 \mathrm{~V}$. Median peak current is of the order of $30000 \mathrm{~A} .{ }^{1}$

Death is caused by either cardiac arrest or damage to the respiratory centre in the brain stem-that is, by an immediate effect on two bioelectrical organs that are particularly vulnerable to electric injury. Cardiac arrest is asystolic in lightning stroke: the heart is thought to undergo massive depolarisation and cease action in an attitude of spasm. If adequate treatment and cardiopulmonary resuscitation are supplied immediately, the chances of survival are remarkably high: Cooper $^{2}$ and Andrews et $a l^{1}$ report that lightning stroke carries a mortality of only about $30 \%$.

Neurological effects of lightning stroke Several mechanisms are supposed to contribute to the cerebral damage caused by lightning stroke. Critchley ${ }^{3}$ thought that the genesis of neurological injuries by lightning stroke was primarily vascular; assuming that neural tissue was a poor conductor, the blood vessels constituted the main routes for the passage of currents through the brain. According to Critchley, large vascular tears may be found in the cerebrum when this has been hit directly. Various forms of intracranial bleeding have been documented, such as epidural and subdural hematomas and a few cases of intraventricular haemorrhage. ${ }^{4}$ Cherington et $a l^{6}$ presented a case of cerebral infarction caused by lightning. Additional mechanisms mentioned have been a thermic effect, electrolytic and electrostatic effects, and a mechanical effect caused by the blast resulting from an acoustic shock wave accompanying the stroke. ${ }^{1}$

In his review Critchley ${ }^{3}$ points out that a direct hit of the brain can have a devastating effect: "... the entire brain and parts of the cord may be swollen, softened and even diffluent." In addition, he describes three more common cerebral effects of lightning and electricity demonstrated in postmortem human material. Firstly, focal petechial haemorrhages are scattered throughout the brain and especially the medulla. They may also be found in the spinal cord, particularly in the grey matter of the anterior horns. Secondly, chromatolysis occurs, especially in the pyramidal cells, the nerve 
cells of the medullar nuclei and the anterior horns, and in the Purkinje cells of the cerebellum. Cherington et al reported clear cerebellar atrophy shortly after lightning stroke. Thirdly, curious wide dilatations of the perivascular spaces are found. They are most numerous in the brain stem and cervical cord. These lesions have been attributed by some to bubbles of gas liberated by electrolysis.

The neurological literature on the clinically observable effects of lightning stroke presents a bewildering variety of acute and late onset phenomena. ${ }^{138} \mathrm{An}$ attempt to get an overview from this literature is hindered by the fact that, in many cases, the path of the current after lightning stroke has remained unknown. Variation in this factor must explain part of the large variation in symptoms reported. Next, it is often unclear whether neurological symptoms were the result of electrical damage or caused by cerebral anoxia resulting from cardiac or pulmonary arrest, or by mechanical impact to the brain. However, a clear distinction can be made between immediate and transient features versus delayed and progressive syndromes. ${ }^{7}$

IMMEDIATE AND TRANSIENT FEATURES

Regardless of the type of hit and the path of the current, survivors of lightning stroke invariably pass through a period of unconsciousness followed by confusion, restlessness, and disorientation. ${ }^{1}$ This implies that there is also amnesia: the victim does not remember being hit, or the hours or days of his confused phase.

Among the acute effects of lightning stroke keraunoparalysis is very common. ${ }^{19}$ This transient paralysis, usually of the lower limbs, manifests itself as a complete inability to move the legs, with complete loss of sensation in them. Peripheral pulses are generally not palpable and the affected limbs take on a pale or blue appearance. Therefore, it is thought that keraunoparalysis is a peripheral phenomenon caused by vasospasms or vasoconstriction. It may resolve quickly, within an hour. ${ }^{9}$

Cerebral oedema has been noted, either on the basis of clinical signs, via $\mathrm{CT},{ }^{1}$ or with MRI. ${ }^{7}$ EEG findings sometimes include focal abnormal activity but more often diffuse abnormal activity such as excess of slow activity or poorly organised background rhythm with low amplitude, consistent with a generalised encephalopathy. ${ }^{8}{ }^{10}$ Seizures, either generalised or focal, are occasionally seen but it is uncertain whether these are primarily electrical or hypoxic in origin. ${ }^{1}$

\section{DELAYED AND PROGRESSIVE SYNDROMES}

In addition to the acute effects, a large variety of late onset phenomena have been reported as being possibly related to lightning stroke. Cherington et $a l^{6}$ mention spinal atrophic paralysis, amyotrophic lateral sclerosis, parkinsonism, progressive cerebellar ataxia, myelopathy, and several neuropathies. Finally, neuropsychiatric symptoms such as personality changes, emotional lability, poor concentration, and forgetfulness have been described as late sequelae of lightning stroke. ${ }^{811} 12$
Critchley $^{3}$ has pointed out that many of the secondary effects of lightning and electricity are "trophic" in character, suggesting an implication of the autonomic nervous system. As examples he mentions cyanosis, peripheral arterial spasm, pupillary abnormalities, and Horner's syndrome.

\section{Neuropsychological effects}

Neurological literature on the effects of lightning stroke has already reported cognitive impairments in some cases, in particular impairments of memory. ${ }^{13}$ Kotagal et al ${ }^{12}$ studied three 11 year old schoolboys who had survived lightning stroke, and reported problems in memory and concentration lasting weeks to months. Case studies including formal psychological assessment have been very scarce. Frayne and Gilligan ${ }^{8}$ reported two cases of lightning stroke, supplying some test data. Their first patient was a 32 year old farmer who had been holding a telephone against his right ear during a thunderstorm. When lightning struck the line he lost consciousness for 15 minutes. Afterwards he complained of headache and vertigo and veered to the left while walking. He also had two periods of complete desorientation and his family noted a personality change, with outbursts of aggression and verbal abuse. Psychological testing, three weeks after lightning stroke, disclosed a pronounced discrepancy between verbal and non-verbal memory and difficulty learning new complex verbal material. The second patient was a 15 year old boy struck on the head by lightning (direct hit). When seen two hours after injury, he was semiconscious, irritated, and aggressive. No focal neurological signs were present but there was a burn on the right posterior parietal scalp. Brain CT showed a small right posterior parietal infarct consistent with the position of the scalp entry wound. A repeat CT at six weeks was normal. Neuropsychological testing showed reduced concentration with some loss in problem solving and slowed coordination. These deficits gradually resolved, although the paper does not specify the duration of the recovery period.

As far as we know, the first case with an extensive, serial neuropsychological assessment and follow up was a 12 year old boy described by Baron et al. ${ }^{10}$ While he was at a sports field this boy received second degree burns as the result of a nearby lightning strike (probably sideflash). Paramedics noted the absence of spontaneous respirations, fixed and dilated pupils, and a possible transient cardiac arrest. After two days the boy regained consciousness, followed commands, and began to talk but was disoriented and confused. Neuropsychological assessments two to four weeks after injury disclosed retrograde amnesia, aphasia, dyscalculia, and reduced auditoryverbal memory. On later occasions, testing disclosed steady progress and two and a half years after injury all problems had disappeared. The boy's mother confirmed a return to his premorbid level of functioning, although "it took a full two years to get there". 
Table 1 Series of patients with sex, age, type of lightning stroke and duration of amnesia after being hit

\begin{tabular}{lll}
\hline Patients & Type of LS & Amnesia \\
\hline F, 38, housewife in tent & Sideflash & $4-5$ hours \\
M, 39, technician holding tentpole & Contact hit & 10 minutes \\
M, 40, farmer handling electric fence & Contact hit & $10-15$ minutes \\
F, 17, student standing by tentpole & Sideflash & Minutes \\
F, 15, student holding rope ladder & Sideflash & 8 hours \\
M, 18, student walking forest road & Direct hit & 5 weeks \\
\hline
\end{tabular}

From this review of the literature it can be concluded that neurological case studies mention mental deficits after lightning stroke in some patients. Neuropsychological case descriptions suggest that impairments in attention and memory can remain for weeks or months after injury, but only one case was studied extensively and repeatedly. Against this background, it seemed useful to present a description of six patients who were studied neuropsychologically after an interval of such duration that their state could be considered stable, at least in a neurological sense. Also, these patients were all tested with the same extensive battery and the possible influence of emotional reactions to the lightning stroke was studied, among other things with a lightning fear scale.

\section{Methods}

Research on the effects of lightning stroke is hindered by the fact that it is well nigh impossible to collect data on a "representative" sample of patients. As mentioned above, the diversity in sequelae is enormous and patients are very scarce. Starting from 1994 we were able to study six patients. Due to our procedure, the sample is biased in that no patients with complete recovery were included: they were all referred to our centre because of lasting complaints. There were three males and three females in the series, their ages ranging from 15 to 40 years.

Two of our six cases are described in detail below. Table 1 gives an overview of the total sample.

Table 2 Tests in the neuropsychological battery

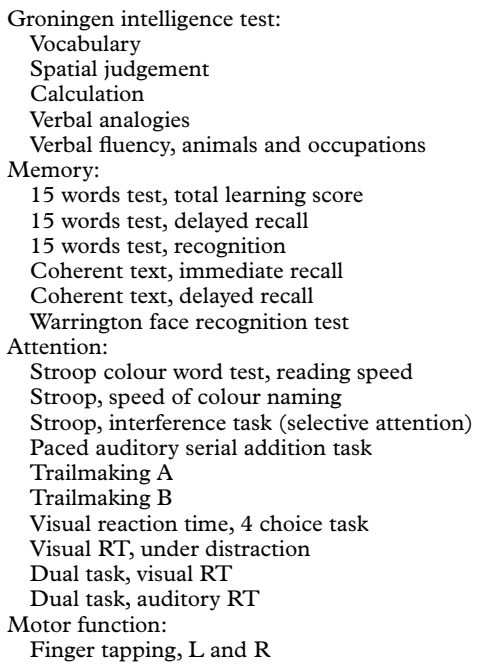


Table 3 The lightning fear scale and the distribution of scores obtained from 50 subjects without lightning stroke experience

\begin{tabular}{lr}
\hline A thunderstorm & \\
\hline 1 Does not scare me at all, I remain indifferent & 4 \\
2 Scares me slightly when I am outdoors & 29 \\
3 Scares me slightly, even when I am indoors & 13 \\
4 Scares me, no matter where I am & 2 \\
5 Scares me very much, I cannot continue & \\
my activities during a thunderstorm & 2 \\
& 0 \\
\hline
\end{tabular}

COMPLAINTS QUESTIONNAIRE

Subjects were interviewed about complaints that were related, in their view, to the lightning stroke. The interview started with an open question about experienced symptoms, so as not to influence the patients in their wording of complaints. After recording the so called "spontaneous complaints", the interview was continued by presenting 31 questions from the head injury complaints list, a questionnaire developed in the Department of Neurology at Groningen for research on the effects of closed head injury. ${ }^{1415}$ This list assesses the presence of complaints by a comparative approach - that is, each question is phrased in such a way that the interviewee is required to compare his or her present state to the preinjury state. This approach was chosen to control for the baseline frequency of complaints, such as headache, in the general population.

NEUROPSYCHOLOGICAL TEST BATTERY

The battery of tests consisted of five subtests of a Dutch intelligence test, the Groningen intelligence test, and of several tests of memory and learning, attention, visual reaction time, and motor function of the hands. Table 2 lists these items. Assessment with this battery lasted about 2.5 hours.

PERSONALITY INVENTORIES AND LIGHTNING FEAR SCALE

The patients were assessed with two personality questionnaires. The first of these, the Amsterdam biographical questionnaire (ABV) consists of four scales: neuroticiscm, somatisation, extraversion, and test attitude (the last one assessing a defensive attitude with denial of emotional problems). The second questionnaire, the Dutch personality questionnaire (NPV), contains scales for inadequacy, social inadequacy, rigidity, dominance, and self appraisal. Whereas ABV and NPV attempt to

Table 4 Frequency of complaints in the series of six patients, as assessed with the head injury complaints list ${ }^{14}$

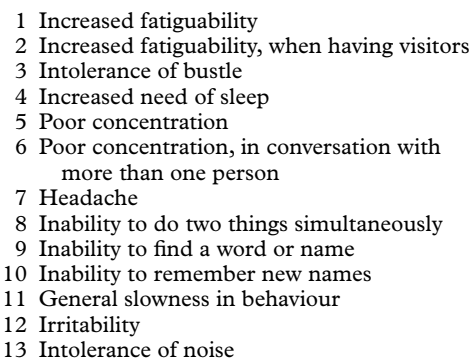

5
5
5
4
4

4
3
3
3
3
3
3
3

measure more or less stable personality traits, the next questionnaire, called symptom checklist, assesses moods and feelings of subjects over the past week. ${ }^{16}$

The lightning fear scale (LFS) was devised especially for this study. It is a six point scale, values ranging from $0=$ "a thunderstorm does not scare me at all, I remain indifferent" to $6=$ "a thunderstorm scares me to death, it makes me panic" (table 3). The usefulness of the scale was tried out by presenting it to 50 hospital staff and patients in a dental surgery (19 males, 31 females). Their scores scattered satisfactorily on it, $84 \%$ of the respondents scoring a value of 2 or 3 , reflecting a sensible awe of thunderstorms.

The patients were asked to rate their fear twice, once as it had been before their injury and once as they judged it after their lightning stroke.

\section{Results}

SUBJECTIVE COMPLAINTS

All but one patient had complaints about their mental functioning that they related to the lightning injury. Increased fatiguability was mentioned spontaneously by four patients. In addition, increased need for sleep was mentioned twice. Further spontaneous complaints concerned emotional lability, irritability, poor concentration, intolerance of bustle, headache, decreased appetite, often feeling cold, and listlessness.

The 31 questions of the head injury complaints list evoked on average 16 affirmative answers from the five subjects having spontaneous complaints. In table 4, complaints with a frequency of three or higher have been listed in descending order of frequency. As the 18 year old boy (patient 6) had no complaints at all, frequencies in the table range from 3 to 5 . Some of the items are specifications of preceding questions, relating an impairment to a given situation (see questions 2 and 6). Question 8 is aimed at problems with divided attention in daily life.

\section{NEUROLOGICAL DATA}

Table 5 presents data on duration of loss of consciousness (LOC) and amnesia and a listing of neurological signs and symptoms in the acute stage.

NEUROPSYCHOLOGICAL EVIDENCE

The judgment of cognitive functioning in the patients had to be normative, as the use of a control group was not feasible with their small number. All scores of patients were interpreted by means of norm tables that corrected for age, educational level, and sex. A score was considered "borderline" if it fell in the lowest decile of the distribution of scores in the normal group. This implies that, purely by chance, $10 \%$ of all patient scores might be borderline A score was considered "abnormal" if it fell outside the normal range - that is, below the poorest score obtained in the testing of subjects without brain damage. 
Table 5 Neurological signs and symptoms in the acute stage

\begin{tabular}{|c|c|c|c|c|c|c|}
\hline & \multicolumn{6}{|l|}{ Patient } \\
\hline & 1 & 2 & 3 & 4 & 5 & 6 \\
\hline LOC & $1.5 \mathrm{~h}$ & Minutes & Minutes & Minutes & 3 minutes & 9 days \\
\hline Cardiac arrest & No & No & No? & No & Minutes & Minutes \\
\hline Respiratory arrest & No & No & No? & No & $?$ & $?$ \\
\hline Amnesia & $4-5 \mathrm{~h}$ & 10 minutes & $10-15$ minutes & Minutes & $8 \mathrm{~h}$ & Months \\
\hline \multirow[t]{2}{*}{ Signs + symptoms } & $\begin{array}{l}\text { Conjunctivitis L } \\
\text { eye }\end{array}$ & $\begin{array}{l}\text { Keraunoparalysis for } \\
1.5 \mathrm{~h}\end{array}$ & Pain in $\mathrm{R}$ side of body & $\begin{array}{l}\text { Conjunctivitis } \\
\text { both eyes }\end{array}$ & Vomiting & Coma \\
\hline & Hearing impaired & Unable to speak & $\begin{array}{l}\mathrm{R} \text { leg numb, unable to } \\
\text { stand }\end{array}$ & & Headache & $\begin{array}{l}\text { Epileptic insult with myoclonus R side } \\
\text { of body } \\
\text { Afterwards complete hypotonia and } \\
\text { areflexia on R side }\end{array}$ \\
\hline CT & - & - & - & - & - & Haematoma in $\mathrm{L}$ thalamic region \\
\hline EEG & $\begin{array}{l}2 \text { months after LS: } \\
\text { paroxysmal } \\
\text { dysregulation over } \\
\text { L temporal region }\end{array}$ & $\begin{array}{l}2 \text { months after LS: } \\
\text { diffusely slow, good } \\
\text { reactivity, no focal } \\
\text { signs }\end{array}$ & - & - & - & $\begin{array}{l}1 \text { day after LS: severely disturbed } \\
\text { triphasic waves over L fronto-temporal } \\
\text { region. Very slow background activity. } \\
9 \text { days after LS: low voltage theta and } \\
\text { delta over L hemisphere }\end{array}$ \\
\hline
\end{tabular}

LS = Lightning stroke.

Table 6 presents the performance of the six patients on the cognitive test battery. Five of them were able to complete the series of tests, but patient 4 , the 17 year old girl, could not do the paced auditory serial addition task as she had poor calculation skill, a pre-existing problem.

Out of a total of 198 scores 43 were suspect - that is, either borderline or abnormal. This amounts to $22 \%$, as opposed to the $10 \%$ that might have been expected by chance in a sample of healthy subjects. Statistically, this effect was highly significant (one sided binomial test of a proportion, $\left.{ }^{17} \mathrm{p}<0.001\right)$. Moreover, the impaired scores were not distributed randomly over the various tests. An accumulation of borderline and abnormal scores was found in two domains: verbal memory and visual reaction times. Three of the six patients did poorly on the 15 word learning test in the initial learning stage, and four patients scores were borderline in the recognition condition after a 20 minute delay. A coherent text was learned and reproduced poorly by two patients. More striking was the fact that four out of six patients obtained scores that were low at the delayed reproduction of the text, 20 minutes after the learning stage. Memory for faces, as tested with the Warrington face recognition test, seemed less sensitive than the verbal memory tests, as only two subjects scored borderline and abnormal.

Visual choice reaction time seemed sensitive to the effects of lightning stroke, half of the patients obtaining borderline scores on the basic task, the four choice reaction. This poor performance cannot be explained as resulting from a poor motivation during the test, as the movement times of these three patients were in the normal range. Movement time is prolonged in cases of poor motivation. Most striking is the performance of the sample on the dual reaction time task, in which subjects have to react by hand to lights and by foot to tones (two modalities, two response modes). In this divided attention task, three patients obtained clearly abnormal scores and another patient scored borderline. The remaining patients showed a relative abnormality not visible in the table: their longest reaction times were in the dual task. This is highly unusual for subjects under the age of 50, as longest reaction times are practically always found in the second condition, called distraction (four choice reaction with distraction by irrelevant lights). So, although two out of six patients with lightning stroke obtained a score in the normal range on the dual task, the total pattern of their scores on the three reaction time tasks was unusual, in the sense that the dual task was performed relatively slowly.

The performance of the boy who sustained a direct hit (patient 6) differed from the performances of the other subjects in two ways: he had a clear motor slowness and an impairment in the Stroop colour word test. The motor slowness is visible in prolonged movement times in the reaction time tasks and in low scores on the fingertapping test. The impairment in the Stroop test is visible in the interference condition that measures selective attention and response inhibition: presentation of the ambiguous stimuli (conflicting colour and word meaning) results in an abnormal slowing of responding.

PERSONALITY AND EMOTIONAL REACTION TO LIGHTNING STROKE

The personality questionnaires used in this study were meant as screening devices - that is, to detect patients whose pattern of complaints might be determined by pre-existing neurotic lability. Four out of six patients were inconspicuous in this regard, obtaining average scores on scales such as neurotiscism, anxiety, and depression. The other two patients ( 3 and 4 ; the farmer and the girl in the summer camp tent) obtained scores that classified them as neurotic and depressed. On neuroticism in the $\mathrm{ABV}$, these patients had scores in the percentiles 95 and 92 . On extraversion of the same questionnaire they scored low and very low, percentiles 26 and 9. In the Dutch personality inventory, both of them scored "high" on the scale inadequacy whereas on self appraisal their scores were "low" and "very low" respectively. In the SCL, which reflects the actual state of a subject, they obtained the scores "high" and "very high" on depression. 
Table 6 Scores of the six patients on cognitive and motor tests

\begin{tabular}{|c|c|c|c|c|c|c|}
\hline & \multicolumn{6}{|c|}{ Patient } \\
\hline & 1 & 2 & 3 & 4 & 5 & 6 \\
\hline \multicolumn{7}{|l|}{ Groningen intelligence test: } \\
\hline \multicolumn{7}{|l|}{ Vocabulary: } \\
\hline Spatial insight & . & . & . & . & . & . \\
\hline Additions & - & . & . & . & - & - \\
\hline Verbal analogies & . & . & . & . & . & . \\
\hline Fluency animals & . & . & - & . & . & . \\
\hline Fluency occupations & . & . & - & . & . & . \\
\hline \multicolumn{7}{|l|}{ Memory: } \\
\hline \multicolumn{7}{|l|}{15 words learning } \\
\hline Total score & . & + & + & . & - & + \\
\hline Delayed recall & - & . & . & . & . & . \\
\hline Delayed recognition & . & + & + & . & + & + \\
\hline \multicolumn{7}{|l|}{ Coherent text } \\
\hline Immediate recall & . & . & - & - & . & . \\
\hline Delayed recall & - & . & - & - & . & - \\
\hline Warrington faces recognition & . & . & + & . & - & . \\
\hline \multicolumn{7}{|l|}{ Digit span WAIS } \\
\hline Forward & . & - & . & . & . & . \\
\hline Backward & . & - & . & . & . & . \\
\hline \multicolumn{7}{|l|}{ Attention: } \\
\hline \multicolumn{7}{|l|}{ Colour word test } \\
\hline Reading & . & . & . & . & . & . \\
\hline Colour naming & . & . & . & . & . & . \\
\hline Colour words & . & . & . & . & . & - \\
\hline Interference & . & . & . & . & . & - \\
\hline \multicolumn{7}{|c|}{ Paced auditory serial addition task: } \\
\hline Rate 3.2 & . & + & . & . & . & . \\
\hline Rate 2.8 & - & . & . & . & . & . \\
\hline Rate 2.4 & - & . & . & . & . & . \\
\hline Rate 2.0 & . & . & . & . & . & . \\
\hline Rate 1.6 & . & . & . & . & . & . \\
\hline Total score & . & + & . & . & . & . \\
\hline \multicolumn{7}{|l|}{ Trailmaking: } \\
\hline Form A & . & . & . & . & . & . \\
\hline Form B & . & . & . & . & . & . \\
\hline \multicolumn{7}{|l|}{ Visual reaction time: } \\
\hline 4 choice reaction & + & . & + & + & . & . \\
\hline Under distraction & . & . & - & . & . & . \\
\hline Dual task, visual RT & + & - & - & - & . & . \\
\hline Dual task, auditory RT & + & . & . & . & . & . \\
\hline Average movement time & . & . & . & . & . & - \\
\hline \multicolumn{7}{|l|}{ Motor function: } \\
\hline \multicolumn{7}{|l|}{ Finger tapping: } \\
\hline Non-preferred hand & - & . & . & . & . & + \\
\hline Preferred hand & . & . & . & . & . & - \\
\hline $\mathrm{L} / \mathrm{R}$ difference & . & . & . & . & . & - \\
\hline
\end{tabular}

The presence of a post-traumatic stress disorder according to DSM-III- ${ }^{21}$ was investigated by means of 10 questions derived from the formal criteria in this manual. One feature of the syndrome was excluded-namely, poor concentration and memory problems. In patients in whom an insult to the brain is a possibility it seems unjustified to interpret these cognitive problems as a sign of an emotional disturbance.

Patients 1, 2, and 6 had no anxiety symptoms at all. The remaining patients gave two, three, and five affirmative answers. Anxiety seemed to play an important part in patient 3 , the farmer who was struck by lightning while putting up an electrical fence. He endorsed five of the 10 signs of post-traumatic stress disorder: recurrent dreams of the event, feeling of detachment or estrangement of others, constricted affect, exaggerated startle response, and sleep disturbance. With these symptoms he fulfilled all criteria for the diagnosis of post-traumatic stress disorder according to DSM-III-R.

Changes in fear of lightning were assessed with the six point scale described in the method section. In four subjects, fear had increased.
For two of them, this meant that their score now fell outside the range that might be considered normal, based on the distribution given in table 3. Patients 3 and 5 (the farmer and the girl with the rope ladder) estimated their fear after the lightning stroke as 4 , this being "A thunderstorm scares me, no matter where I am". Both of them had estimated their fear before injury as 1, this being "A thunderstorm does not scare me at all, I remain indifferent".

\section{Discussion}

As patients were selected on the basis that they had lasting complaints of poor concentration, our conclusions must be tentative. However, the study raises the possibility that lightning stroke sometimes causes lasting subjective complaints and mild neuropsychological dysfunction. This is hardly surprising in cases where the brain has been hit directly, as in patient 6 , or by a sideflash to the skull as in patient 1 . In these patients, the current must have caused an appreciable cerebral insult. However, the complaints of all six patients form a constant pattern, fatigue and lack of energy being the central signs. In the cognitive domain, poor concentration and forgetfulness are common. In the emotional domain, irritability and lability are often reported.

Many questions and methodological problems are encountered in trying to explain the sequelae in these six cases. For example, the pattern of complaints is highly non-specificfor example, the same complaints may be heard from normal subjects after sleep deprivation, from subjects who are recovering from head injuries, and from people who have been under considerable emotional stress for longer periods. Apart from this non-specificity several other questions and problems are encountered. Some of these are discussed below.

Firstly, the actual path of the current can only be guessed in most of our patients, due to the lack of entry and exit burn wounds. This makes it difficult to distinguish between local and general effects. Secondly, the strength of the current - its voltage and amperage-are unknown in all cases. Hence, there are two unknown physical factors that complicate the interpretation of neurological and neuropsychological findings.

Thirdly, detailed information concerning the acute state is usually lacking. Patients had been taken care of by laymen or paramedics, in an early stage, and had often not been assessed neurologically when admitted to a hospital. Basic neurological information such as EEG recordings and CT were not available for some patients in our series. However, as do Kotagal et $a l^{12}$ we think that cerebral hypoxia due to respiratory and cardiac arrest cannot have played a major part in this series. In most patients, there had been no or only very short respiratory arrest.

Cerebral damage due to head injury caused by falling down after lightning stroke is unlikely too in our series. Patient 1 was lying when hit, and the other patients fell down on soft 
surfaces such as grass or the cloth in tents. None of them had been thrown any distance by the mechanical impact of lightning.

In our view, the essential problem in this series of cases is the problem of a possible emotional reaction to lightning stroke. It could be argued that anxiety and depression are factors causing minor cognitive impairments such as forgetfulness and absent mindedness in daily life. Being struck by lightning is a dramatic event and although the amnesia has a certain protective effect, the survivors will inevitably realise that they have been very close to death. Some literature on psychiatric effects of lightning stroke is available. In his review, Critchley $^{3}$ noted that "hysterical manifestations are very common, especially after lightning stroke". Shaw and York-Moore ${ }^{11}$ studied a female patient who was one of the victims when lightning struck the racecourse in Ascot in July 1955 , killing two people and injuring some 20 others. Loss of consciousness for one hour, confusion, and an amnesia lasting 36 hours indicated that the lightning stroke had caused considerable insult to her brain. Afterwards she had a grotesque ataxia and reported anaesthesia of the typical glove and stocking type, signs that were interpreted as being hysterical by the authors. However, anxiety reactions are probably more common than hysterical behaviours. One of the symptoms of the post-traumatic stress disorder as defined by DSM-III-R is "memory impairment or trouble concentrating". Therefore, it is of utmost importance, in our view, to assess the emotional reaction and premorbid personality of lightning stroke victims, along with their neurological and neuropsychological state.

It is our opinion that the lasting complaints and mild cognitive impairments noted in our sample cannot be explained on the basis of anxiety reactions or depression. Only in the case of the farmer, emotional factors may have contributed to his dysfunctioning in daily life.

Hence, the question arises as to what the exact pathogenetic mechanism might be, when lightning stroke leaves permanent sequelae. Speculatively, we raise the question whether the electrical injury in lightning stroke can cause a syndrome of autonomic dysregulation. This speculation is inspired, on the one hand, by complaints of our patients about vegetative symptoms (for example, often feeling cold). On the other hand, our speculation is based on clinical findings reported in previous publications. As mentioned in the introduction of this paper, Critchley ${ }^{3}$ remarked that many of the secondary effects of lightning are "trophic" in character, suggesting an implication of the autonomic nervous system. Benthaus and Hundt $^{18}$ noted that vegetative symptoms are frequent after electrical injury (tachycardia, hyperhidrosis, increased dermography, dizziness, orthostatic collapse, and excessive reaction of blood pressure and pulse to physical effort). The authors summarise these signs under the heading of "vegetative dystonia". They point out that some of their patients may have been vegetatively labile before the electric injury, but they add that the syndrome was also seen in "constitutionally strong, robust, and sturdy labourers". Benthaus and Hundt found autonomic disorders in 17 out of 50 (34\%) patients with electric injuries. Koeppen ${ }^{19}$ found pronounced autonomic disorders in $23 \%$ of his sample. Panse ${ }^{20}$ also states that autonomic disorders are common after electric accidents.

In the case of lightning, it could be speculated that the passage of a $50000000 \mathrm{~V}$ current through the cervical area affects autonomic systems such as the sympathetic trunk. Sympathetic innervation from the spinal segments $\mathrm{C} 1$ and $\mathrm{C} 2$ has an effect on the diffuse reticular system and, among other things, on the regulation of tonus in blood vessels. As mentioned, Critchley ${ }^{3}$ assumed that blood vessels constitute the main routes for the passage of currents through the brain. For the cervical area, this might imply that the plexus sympathicus around the carotic and vertrebrobasilaric arteries sustains electrical damage.

In our view, permanent autonomic dysregulation might explain both the symptoms of fatigue and headache that were so frequent in our series, and the cognitive dysfunctioning experienced in daily life and measured to some degree by the neuropsychological test battery. Concentration and divided attention are aspects of cognition that are easily disturbed by physical factors such as pain and fatigue. However, the hypothesis that an autonomic dysregulation is causing cognitive problems in some lightning stroke patients should be tested by combining neurophysiological recordings with neuropsychological assessment in further studies of survivors of lightning stroke.

1 Andrews CJ, Darveniza M, Mackerras D. Lightning injury - a review of clinical aspects, pathophysiology and injury - a review of clinical aspects, pathophy

2 Cooper MA. Lightning injuries: prognostic signs for death. Ann Emerg Med 1980;9:134-8.

3 Critchley M. Neurological effects of lightning and electricity. Lancet 1934;1:68-72.10.

4 Mann H, Kozic Z, Boulos MI. CT of lightning injury. $A m$ f Neuroradiol 1983;4:976-7.

5 Stanley LD, Suss RA. Intracerebral hematoma secondary to lightning stroke: case report and review of the literature. Neurosurgery 1985;16:686-8.

6 Cherington M, Yarnell P, Lammereste D. Lightning strikes: nature of neurological damage in patients evaluated in hospital emergency departments. Ann Emerg Med 1992;21: $575-8$.

7 Cherington M, Yarnell P, Hallmark D. MRI in lightning encephalopathy. Neurology 1993;43:1437-8.

8 Frayne JH, Gilligan BS. Neurological sequelae of lightning stroke. Clin Exp Neurol 1988;24:195-200.

9 Ten Duis HJ, Klasen HJ, Reinalda PE. Keraunoparalysis, a specific lightning injury. Burns Including Thermal Injury 1985;12:54-7.

10 Baron IS, Haney A, Shelburne S. Lightning injury in a child: case report. F Clin Exp Neuropsychol 1985;

11 Shaw D, York-Moore ME. Neuropsychiatric sequelae of lightning stroke. BMF 1957; ii:1152-5.

12 Kotagal S, Rawlings CA, Chen S, et al. Neurologic, pediatric, and cardiovascular complications in children struck by lightning. Pediatrics 1982;70:190-2.

13 Gathier JC. Neurological changes in a soldier struck by lightning. Psychiatria, Neurologia, Neurochirurgia 1960;63: 125-38.

14 Van Zomeren AH, Van den Burg WH. Residual complaints of patients two years after severe head injury. 7 Neurol Neurosurg Psychiatry 1985;48:21-8.

15 Hinkeldey NS, Corrigan JD. The structure of head-injured patients' neurobehavioral complaints. Brain Injury 1990;4: 115-34.

16 Derogatis LR. SCL-90: administration, scoring, and procedure manual for the revised version. Baltimore: Johns Hopkins University School of Medicine, Clinical Psychometrics Research Institute, 1977 .

17 Hays WL. Statistics. Chicago: Holt, Rinehart, and Winston, 1988. 
18 Benthaus J, H-J Hundt. Herzschäden und vegetative Störungen nach el ektrischem Unfall. Zeitschrift für die gesa-

19 Koeppen S. Erkrankungen der innere Organe und des Nervensystems nach elektrischen Unfällen. Mschr Unfallheilk. Berlin: Springer Verlag, 1953. (Beiheft 34.)
20 Panse F. Electrical trauma. In: Vinken PJ, Bruyn GW, eds. Handbook of clinical neurology. Amsterdam: Elsevier, Handbook of clin $1970 ; 7: 344-87$.

21 DSM-III-R. Diagnostic and statistical manual of mental disorders. Washington, DC: American Psychiatric Association, 1987.

NEUROLOGICAL PICTURE

\section{Post-traumatic cerebral venous sinus air embolism}
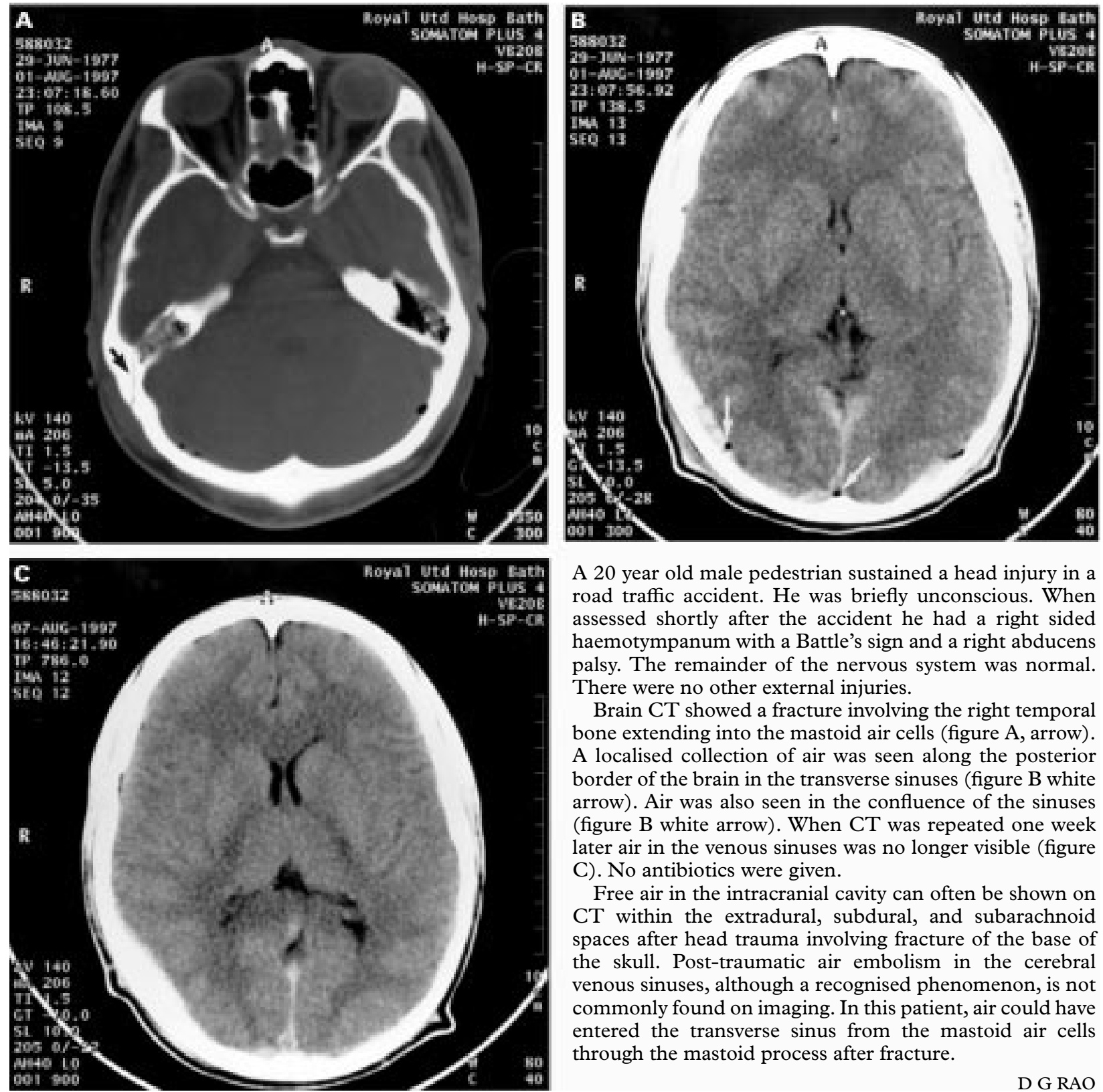

A 20 year old male pedestrian sustained a head injury in a road traffic accident. He was briefly unconscious. When assessed shortly after the accident he had a right sided haemotympanum with a Battle's sign and a right abducens palsy. The remainder of the nervous system was normal. There were no other external injuries.

Brain CT showed a fracture involving the right temporal bone extending into the mastoid air cells (figure A, arrow). A localised collection of air was seen along the posterior border of the brain in the transverse sinuses (figure B white arrow). Air was also seen in the confluence of the sinuses (figure B white arrow). When CT was repeated one week later air in the venous sinuses was no longer visible (figure C). No antibiotics were given.

Free air in the intracranial cavity can often be shown on CT within the extradural, subdural, and subarachnoid spaces after head trauma involving fracture of the base of the skull. Post-traumatic air embolism in the cerebral venous sinuses, although a recognised phenomenon, is not commonly found on imaging. In this patient, air could have entered the transverse sinus from the mastoid air cells through the mastoid process after fracture.

D G RAO P R LYONS Department of Neurology, Royal United Hospital, Combe Park, Bath BA1 3NG, UK

Correspondence to: Dr P R Lyons, Department of Neurology, Royal United Hospital, Combe Park, Bath, BA1 3NG, UK. 